\title{
Geomorphological mapping of granite caves
}

COSTAS VÁZQUEZ, R. ${ }^{1,2}$ SUÁREZ PÉREZ, R. M. ${ }^{1}$ and VAQUEIRO RODRÍGUEZ, M. ${ }^{1,2}$

(1) Clube de Espeleoloxía A Trapa (CETRA)

(2) University Institute of Geology "Isidro Parga Pondal”. Universidade de A Coruña.

https://doi.org/10.17979/cadlaxe.2013.37.0.3741

\section{INTRODUCTION}

The aim is to develop a mapping which represents the relief and the form (morphology) of granite caves and associated superficial structures. As such, it is a representation of the forms and microforms present in the volume that forms the cave (wall, floors and ceilings) and defines the underground landscape:

- Structural elements and forms

- Gravitational forms

- Fluvial and associated erosive forms

- Glacial and periglacial forms

- Aeolian forms

- Depositional forms and speleothems

- Weathering forms

- Polygenic forms 
Elements of anthropic and paleontological origins

All these forms are expressed graphically by combining two types of elements called (MARTIN-SERRANO et al. 2004; pp: 24; RODRÍGUEZ GARCÍA, et al. 2006) forms stricto sensu, and recent and/or superficial deposits or formations.

The first ones are represented by a symbology grouped in sets of common genesis identified with a characteristic color of the morpho-genetic group. The second are areas colored for the projected surfaces and colored outline for the boundaries of the passages (wall, floors and ceiling according to the views).

The geomorphological mapping of these caves is the main device for studying the forms and their genesis, evolution and structure.

\section{CONTENT}

The geomorphological mapping made for each cave is formed by a main plan view map, a map derived from the dissociated plan view and correlating the overlaid levels, and several auxiliary maps and sketches:

- Main plan view map: its purpose is to show the horizontal projection of all the form where it may be seen the extension of the cavity, the orthogonal network of fractures that defines it as well as their movements and rotations, and the relationship between close underground and superficial forms.

- Map derived from the dissociated plan by overlaid levels: though it may be very confusing, it is easy to represent hidden subjacent or superjacent levels in a grouped plan at topographic level. It is impossible to outline the superficial formations of each level at geomorphological level. So, it is created a disassociated plan view as a map derived from the main plan, which allows a direct view of each of the levels and sublevels of the cave. The levels are correlated by means of auxiliary references.

\section{- Auxiliary maps and sketches:}

- Longitudinal sections or main profile map: This section is made combining the projected or developed profiles (VAQUEIRO et al., 2007c) along a polygonal drawn coinciding with the maximum extension of the cave. Developed profiles will be used:

- When the graphic plane is located at about $+/-5^{\circ}$ with respect to the structural plane.

- To include cross-sections in the main plan, i.e. sections of the profile which are not directly correlated with the main plan, and located in levels which are orthogonal to the graphic plane.

- In general, projected profiles will be used when adjacent landscapes, either convergent or not, are correlated with different developments but associated with the same planes or structural discontinuities.

- Complex cross-sections according to the definition given by VAQUEIRO et al. (2007a, 2007c): used to obtain global profiles (at structural level) overlapping and combining the partial sections obtained for the passages of each level of the cavity in one plane.

- Three-dimensional model: its purpose is to allow an easy visualization of the spatial relations among structural elements, levels, sublevels and landscapes. 


\section{BASIC MAPPING}

The official methodology of the Spanish School of Speleology (MARTINEZ I RIUS, 1992; PUCH, 1997) was followed to discretize the underground space along the structural line of the cave landscapes through different open and closed polygonals and radials. The data obtained for the different passages was correlated with the data of adjacent landscapes in order to make global and complex sections of the conduits or galleries defined by the continuous rocky boundaries (VAQUEIRO et al., 2007b).

The itinerary or polygonal method consists of a chained succession of points (topographic survey stations) linked by vectors that are normally called axes (or views). The polygonal method consists of measuring the length (vector module) and the angles (vertical or inclination and horizontal or direction) of these views with respect to planes and reference axes. Each station has information of the landscape definition, LRUD (left-right-up-down) data. It is called radial to a series of topographic measurements taken from one station, clockwise or anticlockwise, to different directions in order to outline the boundaries of a passage or chamber. The basic data LR(UD) of a station are radial to left and right according to the direction orthogonal to the line of the cave.

In the passages where speleothems, microforms, especially sensitive, paleontological or archaeological remains prevail, the instructions given by HILDRETH-WEKER \& WEKER (2006) was followed to perform the topography with the least possible impact. Some areas were not passed along, only making the visible perimeter outline with laser telemetry to avoid the destruction of microforms. Chemical or physical markers were not used to signal the reference topographic stations.

The topographic stations were spaced out according to the space of the discontinuities and the geometry of the cave. The granite caves are characterized by the disjunction of blocks during different structural movements. Also, the stations are set up in discontinuities to establish the situation of the fractures that affect the continuity and uniformity of the passages and determine the local geometry (sharp variation of height and width). The caves were mapped at floor level, plotting the floor.

Topographic data are upla sets that form a line vector or link between two topographic stations and complementary information related to the morphology and dimensions of the passage. The data used are:

- Number of the From station

- Number of the To station

- Distance between stations (module of link vector)

- Direction or horizontal angle between the link vector among the stations and the magnetic north. Mean value of the fromstation.

- Inclination or slope: angle formed by the link vector among stations with respect to the horizontal plane.

- LRUD (Left/Right/Up/Down) as information: topographic stations were set up in the sharp change of section in order to represent the structural and morphological change. When necessary, two sets of data, LRUD- and LRUD+, have been considered (Figure 1). 


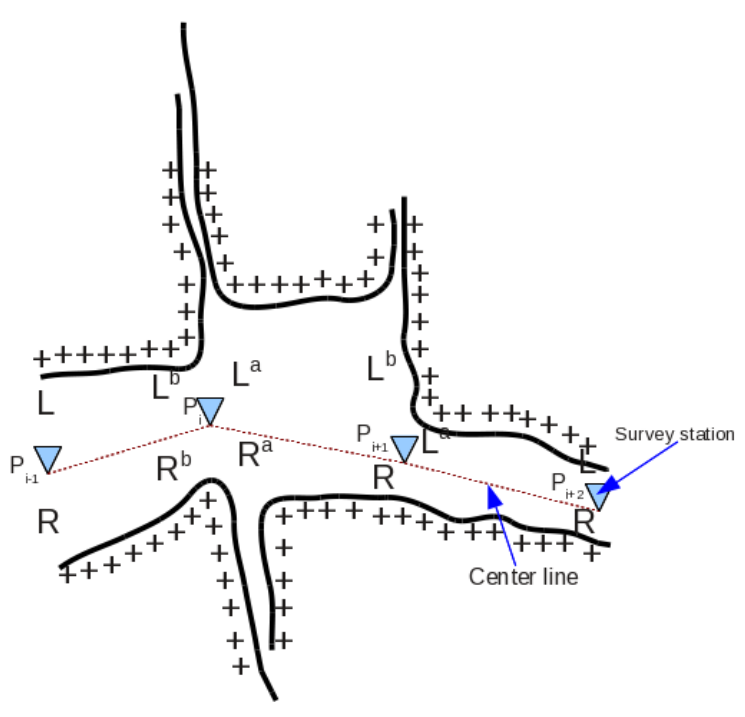

Figure 1. Two different LRUD vectors are considered in each survey station to model the discontinuities sets. Note that station LRUDb is the characterization of passage entering in the station while LRUDa is the characterization leaving the station. Block movements, block rotations or the existence of a discontinuity make LRUDb NOT EQUAL to LRUDa. And both data must be recorder if we want to "trace" the discontinuity. In other situations LRUD are defined like real vectors not necessary orthogonal to the $\mathrm{PiPi}+1$ vector. Then each component (mainly L and $\mathrm{R}$ components) must be defined by the upla (distance, compass, dipping) where distance is the module of $|\mathrm{L}|$ or $|\mathrm{R}|$ in each case. Many cave survey programs do not consider the appropriate use of this information. And passage limits are defined by a single spline line.

\section{EQUIPMENT}

The topographic data were taken with a measuring tape combined with a laser telemeter DL150 Bosch, military compass (2-grade accuracy) and digital clinometer SolaTronic - Fisco (accuracy $0^{\circ} / 90^{\circ}=0.1^{\circ}$ ). When possible due to the dimensions of the landscape or chamber, the horizontal angular measurements were carried out with a level NI020A Carl Zeiss Jena (accuracy 0.1, gon $=0.1^{\circ}$ ).

At present, combined measuring devices are essayed like the Trimble LaserAce 1000 rangefinder (compass: heading accuracy $2^{\circ}$, heading resolution $0.1^{\circ}$; inclinometer: accuracy $0.2^{\circ}$, resolution $0.1^{\circ}$; distanciometer: accuracy $10 \mathrm{~cm}$ (150 $\mathrm{m})$, resolution $1 \mathrm{~cm}$ with the possibility of transmission of lectures in real time for its processing in situ.

The same equipment was used to make the mapping of superficial forms (dolines, surface channels, etc.).

\section{MAPPING ELABORATION}

The base mapping was made manually at 1:100 scale using an equidistance between level curves of $0.5 \mathrm{~m}$. The level curves were determined by interpolation from the topographic nodes defined by the polygonals network. The contours and boundaries were drawn with 0.8 mm thicknesses; the symbology and auxiliaries were drawn at $0.4 \mathrm{~mm}$; the level curves and auxiliaries at $0.2 \mathrm{~mm}$ (MARTÍNEZ I RIUS, 1998 pp: 98). The international symbology UIS-1999 was used as reference. Some complementary symbols accepted by the Spanish School of Speleology were included though they do not appear in the UIS symbology. The base mapping was digitalized in binary mode with 300 pp resolution.

The development of this digital work phase is being evaluated with Therion (www. therion.speleo.sk).

The main and auxiliary geomorphological mapping was made with GIMP (www. gimp.org) to establish the color areas (pre- 
sent forms and deposits). SCRIBUS (www. scribus.net) was used for the post-processing of the derived mapping of the GIMP. The layers of symbols corresponding to the forms, layers of labels and complementary texts were added.

The final geomorphological mapping was exported in PNG format at $100 \%$ of size, $100 \%$ of quality and $150 \mathrm{pp}$ resolution. The resolution was reduced due to the hardware restrictions in the digital post-processing.

Figure 2 represents an example of a main geomorphological map of the O Forno cave (Castelo de Fraiâo or Monte das Furnas, in the Boivâo parish, Valença, Portugal) in two processing phases.
The three-dimensional model was elaborated with the topographic data of the cave using COMPASS software of Fountain Computer product (www.fountainware. com). This software was chosen because it had been used in other topographic projects of large caves, such as the Lechugilla cave (New Mexico) (WIDMER, 1998). Its use is relatively simple but the version used does not allow generating gallery contours following radials. Models have been started to be made with Therion to solve this limitation. Stereoscopic versions (red-cyan anaglyphs) as well as VRML models (Virtual Reality Model Language) were made as derived models. 

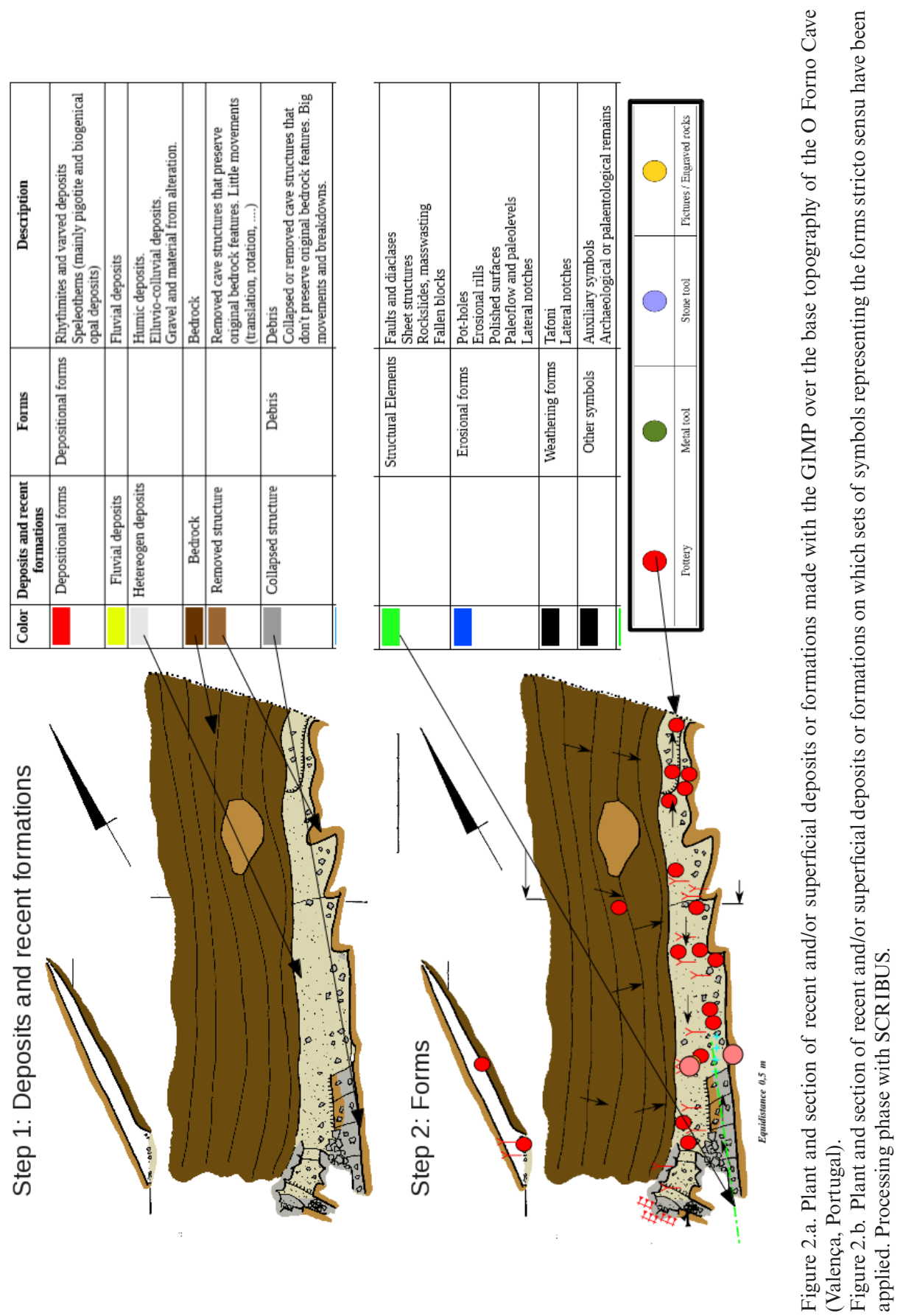


\section{INFORMATION OF THE MAPPING}

\section{Topographic and hydrographic information}

The topographic information sensu stricto reflected on the base mapping (edition E1:100, ep.0.5) was preserved in the derived geomorphological mapping. It is the main layer.

In most cases, the cavity forms part of the local underground drainage network, thus the local hydrographic information is implicit in the base mapping. In the main maps and in some auxiliary views, it was also included the representation and mapping of the superficial watercourses signaling the absorption, capture and spring points of the underground network. The secondary contributions (underground springs) were also included and indicated.

\section{Lithological information}

According to their maximum dimensions, granite cavities are meso- or microforms (VAQUEIRO et al., 2007b) associated with only one type of substratum, mainly granites, granitoids and gneisses. Therefore, the substratum would be represented by a layer of uniform color but it was omitted.

In certain cases, sedimentary rocks (conglomerates, rythmites, speleothems, ...) were located and mapped thus being represented as color area with specific symbols for the morphology if necessary.

\section{Genetic information}

Following the scheme proposed by MARTIN-SERRANO et al. (2004, pp: 2627), the organization of the elements of the different maps are established considering their main genesis:
Elemental structural forms: directly related to the geological and tectonic architecture of the substratum.

Gravitational forms: related to unsteadiness and structural movements with different evolution grades.

Chemical and physical weathering in magmatic rocks.

Elements related to water flows: erosion forms not limited to the permanent watercourses. The erosion forms present in paleoflows and paleo-levels are included.

Depositional forms: sedimentary deposits (including fluvial, lacustrine, subglacial, littoral and aeolian deposits) and speleothems (mainly of opal-A, evansite, pigotite).

Other forms or elements:

Anthropic, due to diverse troglodyte activities.

Paleontological, coming from the fossil fauna located in the cave.

\section{Chronological information}

One of the objectives of the auxiliary maps (VAQUEIRO et al., 2007b) was to enable the establishment of relative chronologies or sequences from the cartographic relationship between the levels (and paleolevels) and/or related deposits.

The depositional forms were specially taken into account for possible dating (pigotite speleothems, opal-A speleothems, rythmites, terraces, etc.). Remains of anthropic or paleontological origin were included to establish a correlation, at least Holocene, with the rest of the elements considered in the cartography.

In the mapping, certain references are established either by means of specific letters or showing the absolute age of the dated element (age in yr or kyr cal.BP). 


\section{Information on active processes}

When necessary, the state or evolution of the form was signaled with the date of the event in order to draw or follow the evolution of the system. Topo- graphically, the state/magnitude of the process as well as its localization are established, and the timestamp of the event is numbered. This information has a relative validity due to the scale of the studied forms. (Figure 3).

Figure 3. Information on active processes: it may be seen the follow-up made to the sinkhole located in the absorption of the granite system of $\mathrm{O}$ Folón and to the changes in the insurgence point of this transfluence cave.

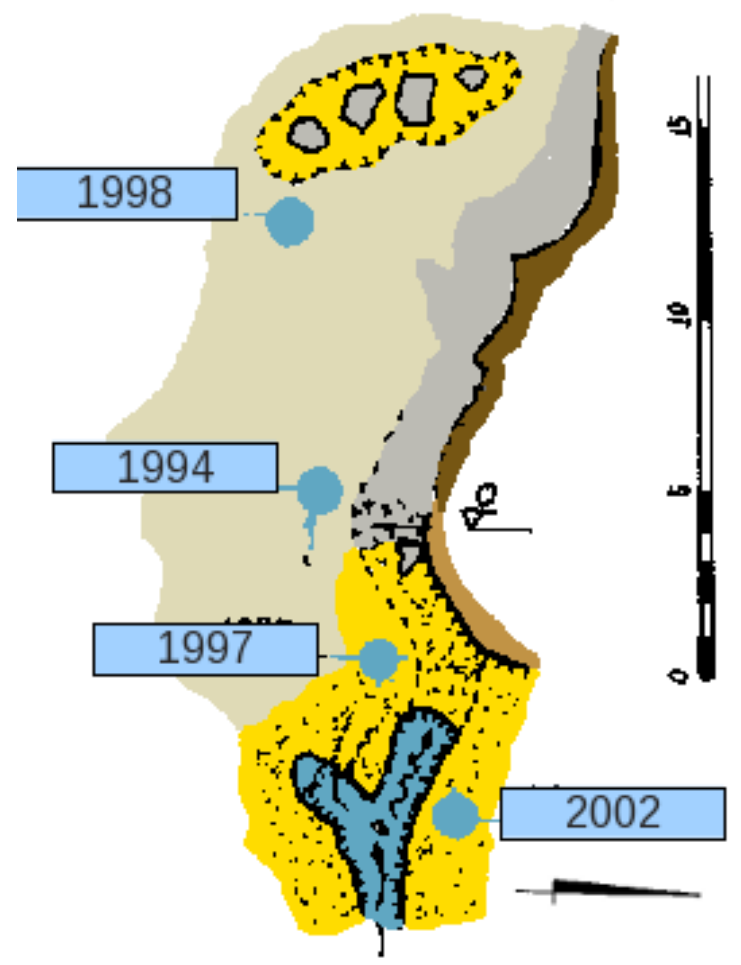

Floods (and other associated depositional processes) were not represented. The active watercourses were represented in their mean flood, except the superficial ones which were represented at their maximum level. Symbols were used (UIS, 1999; FEE: MARTÍNEZ I RIUS, 1992), especially for security reasons other than geomorphological ones, indications of the sinkhole areas during floods were included marking the maximum water levels.

\section{RECENT AND/OR SUPERFICIAL DEPOSITS OR FORMATIONS}

They are the sediments and rocks located in the lithosphere/boundary interphase of the passage (surface, wall or ceiling) of reduced thickness with or without genetic relationship with the substratum, but closely related to the evolution of the cave and the present relief of which they are their lithologic and correlative expression. On the 
other hand, in the areas not covered by sand deposits, an assessment of the morphostructural state of the substratum is represented. These superficial formations are characterized by:

The morphogenetic group to which they belong: the colored areas identifying the formation for the surfaces projected horizontally. The same colors are used for the sections and profiles outlining the boundaries of the passages.

Their age: when there is a specific dating, it is indicated with a complementary label.

Their association with one or several forms: when recent deposits or formations (color areas) coincide in the main map with certain overlaid formations (generally on ceilings), both of the same morphogenetic group, and therefore of the same color, we used views, partial sections and auxiliary clarifications.

The color area may be complemented with the inclusion of some normalized symbols (Blocks-Debris; Pebbles; Clastic elements - Sand-Silt-Clay-Humus).

A particular case is the varved deposits or rythmites: they are cyclic deposits, formed in lakes, pools, ponds associated with floods, ice ablation, etc. Generally, they are formed by a repetition of pairs of very thin, dark and clear layers of fine-grained sediments (silts, clays). Each pair determines an annual cycle, so they may be used to establish a relative chronology when an absolute chronology is not possible. Within a cave, these types of deposits correspond to occasional floods. The color area is complemented with strokes according to the model of figure 3 (see varves): For example, in the structural granite system of O Folón, the rythmites (of unknown age) represent a continuous period of "stagnated" waters during half century.

\section{FORMS SENSU STRICTO}

The forms are the elemental aspects of the relief and the underground landscape, geometric entities that will be represented as specific, linear or superficial elements, by means of a symbol grouped in sets of common genesis identified with a characteristic color.

For their representation, the normalized symbology proposed by the International Union of Speleology (UIS, 1999) was used as reference. Some complementary symbols of the Spanish School of Speleology (MARTÍNEZ I RIUS, 1998) were used; and new symbols (VAQUEIRO et al., 2007c) were established to represent specific microforms related to pseudokarst in granite rocks.

The color represents the morphogenetic group of the form. The same symbol may appear in different groups (by assimilation of the visible form). The color is established by the genesis.

\section{Depositional forms}

As microforms sensu stricto, this morphogenetic group comprises all the speleothems of the pseudokarstic granite caves.

There are two main groups of spleothems: pigotite speleothems, whose visible forms are similar to the ones in karstic caves, while opal-A ones (biogenic opal) have very specific visible microforms. They are represented with standard UIS symbols. The distribution of the symbol indicates the localization of the main forms:

- Dripstone: stalagmites, stalactites and columns. Generally, the pigotite speleothems are represented like this though in some cases these forms are used to represent groups of biogenic 
biogenic speleothems.

- Composite dripstone-flowstone forms: This sub-group includes all the sinter curtains and combinations of similar stalactites.

- Flowstone

- Opal-A speleothems: Except for those cases in which the speleothem may be directly associated with dripstone or flowstone, all opal speleothems of clublike, grass-shape, brotoidal types are generally represented with the same UIS symbol used for cauliflowercalcite morphology. The symbol is used to indicate the existence of opal microforms of different types grouped and concentrated on the rocky surface.

\section{STRUCTURAL FORMS (VAQUEIRO ET}

\section{AL. 2007C)}

- Not open discontinuities with dipping indication. Used to indicate the dipping of a not open discontinuity or the dipping of a set of discontinuities in which sheltertype structures have been developed, as well as to indicate weathering factures and planes with small openings (less than $30 \mathrm{~cm}$ ) or without them. Arrow perpendicular to the fracture direction. The dipping is indicated with a number.

- Open discontinuities with dipping indication: used to indicate the dipping of an open discontinuity or the dipping of a set of discontinuities through which galleries or paleolevels have developed. Long stroke parallel to the fracture direction. The dipping is indicated with a number.

- Sheet structures with sliding: symbol oriented to the direction of the sliding. The distribution indicates the localization and main directions.

- Breakdown doline/collapse limits: to represent the perimeter of superficial depressions associated with cave collapses. Generally, convex depressions that may represent or not lateral stepping. Distribution drawing the external perimeter of the collapse.

- Block fall/collapse/subsidence: variable dimension and according to the magnitude of the process to be represented. The arrow shows the movement direction. The distribution of the symbol indicates the localization of the collapse.

\section{Erosion forms}

It is included all the polished forms produced by mechanical erosion (evorsion) by rotating/whirling water that may carry sand and gravel. In general, they indicate the present or past circulation in vadose regime (turbulent):

- Potholes: are single erosional bowls or moulines, mainly rounded by the swirling current, in a stream bed. They may be located forming groups of overlaid, bound or associated forms. The symbol used is the one proposed by the FEE (MARTÍNEZ I RIUS, 1992).

- Rills: are linear and polished forms engraved on eroded surfaces. The UIS symbol for Anastomosen - Karren is used, but with the color corresponding to the morphogenetic group of the erosion forms.

- Lateral notches by erosion: there are two types of lateral notches in granite caves: ones of erosional origin and others related to weathering processes. Both are represented with the symbol notches (VAQUEIRO et al., 2007c) assigning the color corresponding to their morphogenetic group.

- Paleoflows and paleolevels: abandoned levels which correspond to different sectors of fossil underground flows in 
which erosion forms (polished surfaces, erosion rills, potholes, lateral notches, ...) and depositional forms of fluvial origin (terraces, pebbles, ...) may be identified. The UIS symbol Paleoflows is used. They may be combined with signals of depositional forms (deposits, rythmites) or erosion forms to indicate the circulation direction of the paleoflow at the represented level. The distribution shows the development of the paleochannel, paleolevel or paleoflow.

In some cases, old erosion forms or deposits may be modified or altered by an exhumation or reactivation of the level. The term exhumation is used to describe the removal process of the infills and the sedimentary cover that defined a paleokarstic feature. The term reactivation is used to indicate that a process of cave formation has started again on a morphologic element which has been inactive during a long period of time.

The solution taken is to signal the isolated fossil forms of the present flow as paleolevel-paleoflow. In some areas of the cave where reactivations have been detected affecting the oldest deposits, the type of deposit was identified (rythmites, terracettes, terrace,...). There are systems that present polyphasic landscapes in which different stoppage, reactivation and exhumation stages are overlaid producing processes of evorsion, sedimentation, deposition-encroaching. In such cases, no specific mark was established to avoid confusion. The genetic and chronological information is established in auxiliary views and in the corresponding memory.

\section{Weathering forms}

- Tafone: to indicate the presence of a not mapped tafone (VAQUEIRO et al., 2007c). The symbol is located on the perimeter of the front or plane where the form is.

- Rills (pseudo-karren, pseudo-rills): the UIS symbol for Karren is used, but with the color corresponding to the morphogenetic group of the weathering forms. The arrow is perpendicular to the notch. The symbol is distributed on the affected surfaces.

- Weathering microforms: it is used to represent other types of weathering microforms such as alveoles, weathering walls (weathering microforms (VAQUEIRO et al., 2007c). When the forms are not big enough to be plotted, the symbol indicates their localization, but otherwise the symbol is distributed along the perimeter of the front or plane where the process is developing.

- Lateral notches: used to indicate the presence of lateral notches produced by weathering. The symbol lateral notches - is used (VAQUEIRO et al., 2007c). Variable dimension and according to the form to be represented. The arrow is perpendicular to the notch. The symbol is distributed on the perimeter of the overexcavated wall or plane where the form is located.

\section{Polygenic forms}

Polygenic forms are those forms that need more than one process (genetically) to give place to the final visible form.

- Onglets or pressure scales: these forms are convex surfaces developed by the concentration of charges on the contact point between hanging blocks and walls/ rocky surfaces of the cavity or even between blocks. The symbol indicated in (VAQUEIRO et al., 2007c) is used. The distribution of the symbol indicates the main localization of the form or set 
of forms.

- Paleoseismics and neotectonics: the configuration of some karstic speleothems allows establishing different structural events that the territory underwent. Consequently, these deposits may be used satisfactorily in tectonic and paleoseismic studies (BINI et al., 1992). So, when at local level stalactites are observed to be displaced or broken, and whose displacements seem to be oriented or related to a main structure plane of the system, the breakage of said stalagtites and associated composite forms may indicate movements or neotectonic events (COLLINA-GIRAD, 1996). The same criterion was used for granite caves.

- In general, and unless specific symbols are established for certain forms, these forms will be assigned with the symbol corresponding to the main speleothem but using the green color, which is characteristic of this group of polygenic forms.

\section{Underground courses}

The main course that forms the system is represented with a color area. Indicators of the flow direction may be added.

- Anastomosis: the UIS symbol Anastomosen to indicate the existence of a poorly directed flow (anastomotic). The length and size of the symbol is according to the extension of the represented form.

- Permanent or seasonal sumps (siphon, sump or trap): a cave passage in which the ceiling dips below the water surface. The zones of temporal or permanent sumps were signaled with the indicator (S). When they are temporal, the flooding levels are indicated with a number.

- Dripping areas: areas in which the water contribution is made by dripping. The symbol used is a cross made with stroke type G ISO 128-82 (MARTÍNEZ I RIUS, 1992).

- Underground springs: secondary contributions not related to the transfluence course. They are represented with the FEE symbology (MARTÍNEZ I RIUS, 1992). The symbol was colored in cyan to highlight the type of contribution with respect to the main course.

- Absorptions (input point, insurgence): used to mark the points where the superficial waters penetrate the subterranean conduits. They are represented with the FEE symbology (MARTÍNEZ I RIUS, 1992).

\section{Other forms and elements}

- Note on archaeological materials: the normalized symbol UIS-1999 (human activity) used to represent the subterranean anthropic activity (presence of remains, artifacts, etc...) was replaced by a circumference of black border and a circle with the characteristic color of the nature of the material or deposit without assigning any chronostratigraphic reference to said material. See Figure 2.

- Note on paleontological materials: The normalized symbol UIS-1999 (bones) was complemented including a character code to assign the species according to their taxonomic classification of Linnaeus.

\section{RESERVED COLORS}

Colors have been reserved for auxiliary references (salmon: depth related to 0-height of the cavity) and not strictly geomorphological complementary information (basic orange: references of projection planes or development of composed sections and partial cross-sections). 


\section{RESULTS AND EXAMPLES}

Figure 4 shows the highest sector of the central doline of the granitic system of $\mathrm{O}$ Folón (Vigo, Galicia - Spain). The sector corresponds to the active course (level L5) and close paleolevels (L4 and L3). The most superficial levels were suppressed to see better the strokes of $\mathrm{L} 5$, course reactivated over L4. The deposits of rythmites mark the flooding levels reached during the course blockage after the collapse of the doline.

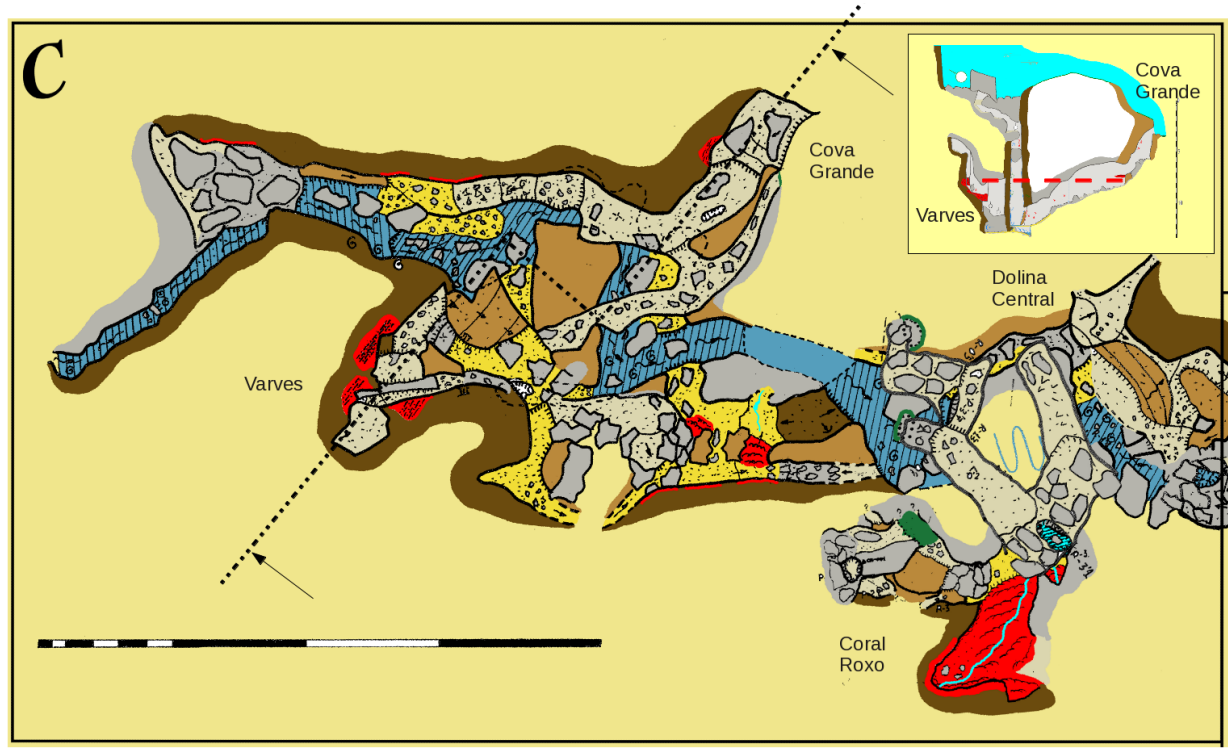

Figure 4. Geomorphological mapping of the structural system of "O Folón", Vigo (Galicia, SPAIN). Plan view sector C: "Cova Grande - Dolina Central": Recent deposits and formations. Over transversal section, correlation of levels of rythmites.

Figure 5 shows a plan view of the Féveros sector of the seismic-tectonic system of A Trapa (Tuy, Galicia - Spain). Several auxiliary views and derived mapping were made from the main map. The correlation among these levels appears in the complex transversal sections A and B-B'. The co-existence of incompatible morphogenetic groups on the same profiles allows the estimation of the succession of fluvial inactivity, exhumation and reactivation episodes of the different levels. The inclusion of chronological data permits to establish temporal references to these episodes. 

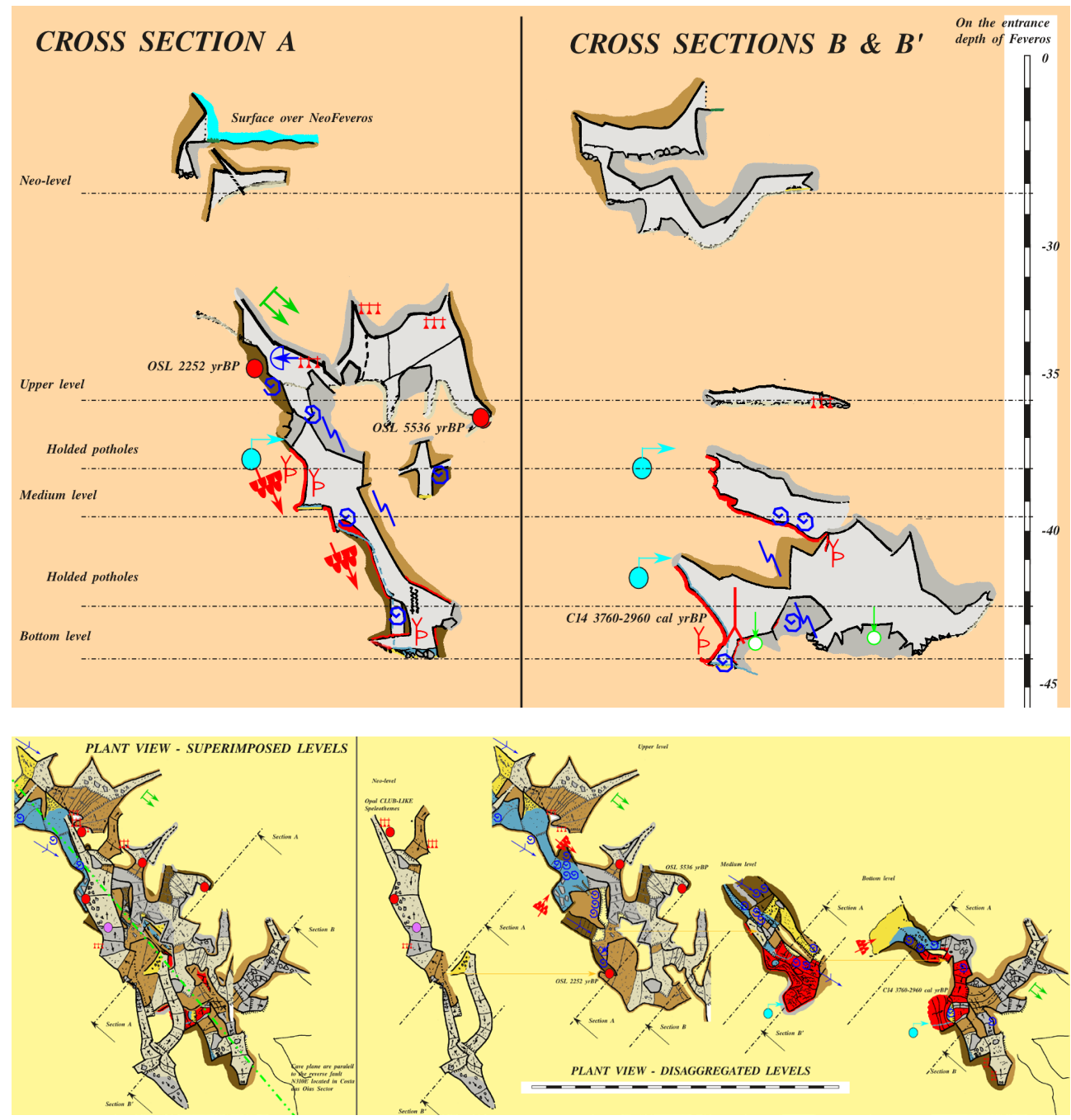

Figure 5. Geomorphological mapping of the seismic-tectonic system of A Trapa (Tuy, Galicia - Spain) (5.a). Plan view of the Féveros sector. Several auxiliary views and derived mapping were made from the main map (5.b).

\section{DISCUSSION}

The absence of continuous boundaries in the landscapes of granite caves is the main problem for their representation and topography. A simplification of the plotting with- out considering the existence of boundaries makes a false representation. The inclusion of details creates some complicated plan or plot views and it is not easy to be analyzed.

In this work, it is proposed the use of a few colors, associated to groups of forms/ 
processes in order to facilitate the representation as well as the visualization of the cave. It is a labored phase of the mapping work and conditions the result for the interpretation and evaluation that the topographer of the landscape and forms performs.

\section{BIBLIOGRAPHY}

BINI, A., QUINI, Y., SULES, O. and UGGERI, A. (1992). Les movements tectoniques récents dans les grottes du Monte Campo dei Froi (Lombardie, Italie). Karstologia 19, pp 23-30.

COLLINA-GIRAD, J. (1996) - Prehistory and coastal karst area: Cosquer cave and the "Calanques" of Marseille. Karstologia 27, 27-40.

HILDRED-WERKER, V. and WERKER, J. C. (2006). Cave Conservation and Restoration. National Speleological Society. Huntsville, Alabama (USA), 188-192.

MARTÍN-SERRANO, A., SALAZAR, A., NOZAL, F. and SUÁREZ, A. (2004). Mapa Geomorfológico de España a Escala 1:50.000. Guía para su elaboración. Instituto Geológico y Minero de España. Madrid.

MARTÍNEZ I RIUS, A. (1992). Topografía Espeleológica. Federación Española de Espeleología. Badalona.

PUCH, C. (1997). Cuevas y Simas: Cómo Representarlas y localizarlas. Edita: Espeleo Club de Gràcia. Barcelona. pp: 35-38. RODRÍGUEZ-GARCÍA, J. A. and PÉREZ-CERDÁN, F. (2006). Normas de organización de la información del Mapa Geomorfológico Nacional digital (versión 1.0 - noviembre 2006). Informe Técnico. Tecnologías y Sistemas de la Información. Sistemas de Información
Geográfica (TSIG). Instituto Geológico y Minero de España.

UIS (1999). Basic Cave Mapping Symbols: The Official UIS list. UIS Working Group on Cave Survey and Mapping. UIS Informatic Commission. International Union of Speleology.

UIS (2005). Karst Surface Map Symbols UIS Working Group on Cave Survey and Mapping. UIS Informatics Commission. International Union of Speleology - Karst Commission of the International Geographical Union (IGU).

VAQUEIRO RODRÍGUEZ, M., BARREIRO BEN, B., COSTAS VÁZQUEZ, R., SUÁREZ PÉREZ, R. and GROBA GONZÁLEZ, X. (2006) Rebuilding paleoflows and structures in the granitical system cave of "O Folón" (Vigo, Galicia - Spain). Cadernos do Laboratorio Xeolóxico de Laxe. Vol. 31, pp. 88-105.

VAQUEIRO RODRÍGUEZ, M., GROBA GONZÁLEZ, X. and VIDAL ROMANI, J. R. (2007) The Granite Structural System of "O Folón”. Coruxo - Vigo (Galicia, Spain). Poster: Special Edition for The International Conference on Granite Caves. Artes Gráficas ROEL. Depósito Legal: VG 855-2007. Vigo.

VAQUEIRO RODRÍGUEZ, M., BARREIRO BEN, B., COSTAS VÁZQUEZ, R. and SUÁREZ PÉREZ, R. (2007). Mapping and modelling of granite cavities: Problems in the representation of forms and work scale. Proceedings International Conference on Granite Caves. A Coruña, 2007. Cadernos do Laboratorio Xeolóxico de Laxe. Vol. 33.

WIDMER, U. (1998). LEHUGUILLA, Jewel of the underground. Published by Speleo Projects. USA. 